\title{
Otimização da extração e amplificação de DNA de dendezeiro: folhas em diferentes fases de desenvolvimento
}

\author{
Extraction optimization and amplification of oil palm DNA: leaves at different \\ phases of development
}

\author{
João Pedro de Andrade Bomfim ${ }^{\mathrm{I}}$, Laiana Pinheiro de Lima ${ }^{\mathrm{II}}$, \\ Cláusio Antônio Ferreirade Melo ${ }^{\mathrm{III}}$, Ronan Xavier Corrêa ${ }^{\mathrm{IV}}$, \\ Fernanda Amato Gaiottov , Antônia Marlene Magalhães Barbosavi
}

\begin{abstract}
Resumo
O objetivo deste estudo foi otimizar e estabelecer um protocolo visando elevar a qualidade e quantidade do ácido desoxirribonucleico (DNA) extraído de folhas, em diferentes estágios de desenvolvimento e conservação, coletadas em plantas adultas e plantas jovens. Além disso, almejou-se padronizar a amplificação via reação de polimerase em cadeia (PCR) e selecionar os marcadores de inter sequência simples repetida (ISSR) de Elaeis guineensis (dendezeiro). O protocolo brometo de cetiltrimetilamônio $(\mathrm{CTAB})$ modificado, devido à suplementação com betamercapto etanol $(0,3 \%)$ e polivinilpirrolidone (PVP) (3\%) no tampão de extração e CTAB $10 \%$ com $1,4 \mathrm{M}$ de $\mathrm{NaCl}$ a 20 min de incubação, a $65^{\circ} \mathrm{C}$, resultou em melhorias qualitativas e quantitativas na extração do DNA, mas com variações entre amostras, provavelmente, devido às variações na degradação e estágio de desenvolvimento das folhas. Foram utilizados dois protocolos de PCR (I e II) para a amplificação do DNA, os quais diferiram principalmente com relação à presença de albumina de soro bovino (BSA) e concentração de primer. Não foi realizada a correlação entre amplificação via PCR e qualidade de DNA, obtidos de folhas danificadas ou sadias, mas se observou que a adição de BSA $(0,075 \mathrm{mg} / \mathrm{mL})$ e o aumento na concentração de primer $(0,5 \mathrm{pcmol})$ (protocolo II) resultou em bandas mais intensas e distinguíveis, porém se ressalta que a qualidade do DNA foi essencial para uma boa amplificação, considerando-se todas as amostras. A amplificação do DNA com o protocolo II possibilitou a seleção de cinco primers: UBC 807, 810, 812, 834 e 848; os quais foram utilizados para a amplificação de13 famílias, compostas de uma planta parental e oito progênies cada.
\end{abstract}

Palavras-chave: Elaeis guineensis; PCR; ISSR

\begin{abstract}
The objective of this study was to optimize and establish a protocol to enhance the quality and quantity of deoxyribonucleic acid (DNA) extracted from leaves under different development stages and conservation conditions collected from mature plants and seedlings. Furthermore, we aimed to standardize the polymerase chain reaction (PCR) and select an inter simple sequence repeat (ISSR) marker for Elaeis guineensis (oil palm). The modified cetyltrimethylammonium bromide (CTAB) protocol, which used $\beta$-mercaptoethanol (0.3\%) and polyvinylpyrrolidone (PVP 3\%) supplementation in the extraction buffer and $10 \%$ CTAB with $1.4 \mathrm{M} \mathrm{NaCl}$ for a 20 -min incubation at $65^{\circ} \mathrm{C}$, resulted in improved DNA quality and quantity. However, this protocol presented variable results among samples, probably due to variations in leaf degradation levels and development stages. The two PCR protocols (I and II) for amplifying the DNA, differed mainly in the presence or absence of bovine serum albumin (BSA) and primer concentration. Although, a correlation between PCR amplification and the quality of the DNA extracted from leaves was not established, the addition of BSA $(0.075 \mathrm{mg} / \mathrm{mL})$ and the highest primer concentration ( $0.5 \mathrm{pmol})$ (protocol II) resulted in more intense and distinguishable bands on gel electrophoresis. DNA quality was essential for a satisfying amplification, considering all the samples. The use of protocol II allowed the selection of five primers: UBC 807, 810, 812, 834, and 848; these were used in the amplification of the DNA extracted from 13 families consisting of one parental plant and eight progenies each.

\section{Keywords: Elaeis guineensis; PCR; ISSR}

\footnotetext{
Engenheiro Agrônomo, Doutorando do Programa de Pós-Graduação em Agronomia/Proteção de Plantas, Universidade Estadual Paulista "Júlio de Mesquita Filho", Av. Universitária, 3780, Bairro Altos do Paraíso, CEP 18610-034, Botucatu (SP), Brasil. pedroab261@hotmail.com (ORCID: 00000001-6292-2439) de Andrade, Rod. Jorge Amado, Km 16, Salobrinho, CEP 45662-900, Ilhéus (BA), Brasil. lanna.pinheiro@hotmail.com (ORCID: 0000-0001-7281-0967) Biólogo, Dr., Bolsista Pós-Doutorando na Universidade Estadual de Santa Cruz, Universidade Estadual de Santa Cruz, Campus Soane Nazaré de Andrade, Rod. Jorge Amado, Km 16, Salobrinho, CEP 45662-900, Ilhéus (BA), Brasil. clausiomelo@gmail.com (ORCID: 0000-0001-9007-1731) Salobrinho, CEP 45662-900, Ilhéus (BA), Brasil. ronanxc@uesc.br (ORCID: 0000-0002-4010-1565)

Bióloga, Dra., Professora da Universidade Estadual de Santa Cruz, Campus Soane Nazaré de Andrade, Rod. Jorge Amado, Km 16, Salobrinho, CEP 45662-900, Ilhéus (BA), Brasil. gaiotto@uesc.br (ORCID: 0000-0002-7140-565X) Salobrinho, CEP 45662-900, Ilhéus (BA), Brasil. ammbarbosa@uesc.br (ORCID: 0000-0001-9540- 4494)
}

II Bióloga, Mestranda do Programa de Pós-Graduação em Genética e Biologia Molecular, Universidade Estadual de Santa Cruz, Campus Soane Nazaré

Iv Engenheiro Agrônomo, Dr., Professor da Universidade Estadual de Santa Cruz, Campus Soane Nazaré de Andrade, Rod. Jorge Amado, Km 16,

vi Engenheira Agrônoma, Dra., Professora da Universidade Estadual de Santa Cruz, Campus Soane Nazaré de Andrade, Rod. Jorge Amado, Km 16,
\end{abstract}




\section{Introdução}

O dendezeiro (Elaeis guineensis Jacq) é uma palmeira de origem africana que se dispersou por várias partes do mundo devido à sua elevada capacidade adaptativa e ao interesse na exploração comercial de óleo, que pode ser extraído do mesocarpo (óleo da polpa) e da amêndoa (óleo de palmiste) do fruto. A importância econômica dessa cultura se deve, em grande parte, à produção de óleo extraído do mesocarpo, que pode ser empregado, por exemplo, na indústria alimentícia e como biocombustível. Apesar de ocupar apenas $5 \%$ da área total mundial, a cultura é responsável por 33\% do óleo vegetal e $45 \%$ do óleo comestível em todo o mundo (SINGER et al., 2013).

O dendezeiro encontra-se no estado nativo, seminativo e/ou cultivado na África e na Ásia (CORLEY; TINKER, 2015). No Brasil, os plantios comerciais estão principalmente nas regiões Norte e Nordeste (SATO et al., 2017); a Bahia, em particular, possui uma área considerável de dendezeiros subespontâneos situados no continente e no litoral. A exploração comercial da cultura apresenta alguns entraves, relacionados a características da planta, que dificultam ou atrasam a obtenção de genótipos promissores a serem utilizados para vários fins. O dendezeiro é uma planta perene com um longo ciclo reprodutivo e requer uma grande demanda de terra para testes de campo e com genótipos obtidos via seminal, pois, segundo Singer et al. (2013), as alterações epigenéticas restringem o uso comercial de clones.

A variabilidade restrita da cultura e a necessidade da busca de novos germoplasmas e/ ou caracterização de populações naturais e subespontâneas requerem tempo, principalmente se forem baseadas apenas em medidas morfoagronômicas. A biotecnologia, e em particular o uso de marcadores moleculares, é imprescindível para alavancar as pesquisas em dendezeiro. Vários marcadores e protocolos de extração de ácido desoxirribonucleico (DNA) têm sido utilizados e adaptados para a maior eficiência no uso da técnica de reação de polimerase em cadeia (PCR), que é dependente da qualidade e amplificação do DNA e da seleção de iniciadores (primers) que discriminem os genótipos. Protocolos foram desenvolvidos e modificados para a extração de DNA de dendezeiros visando redução de custo, tempo e qualidade do DNA (SUZANA et al., 2015; LHASE et al., 2016), porém o protocolo do brometo de cetiltrimetilamônio (CTAB) está sendo utilizado para a obtenção de DNA de dendezeiro, para uso com os mais variados tipos de marcadores moleculares (SUZANA et al., 2015; GOMES, 2016). Marcadores de Inter Sequência Simples Repetida (ISSR) estão sendo utilizados com eficiência no gênero Elaeis para a avaliação da diversidade genética e caracterização de germoplasma de dendezeiro (CHAGAS et al., 2015), mapeamento de híbrido interespecífico (Elaeis oleifera $\times$ Elaeis guineensis) (NORDIANA et al., 2014) e avaliação molecular de dendezeiros regenerados por embriogênese somática (GOMES, 2016). O marcador molecular ISSR é baseado em PCR e amplifica fragmentos de DNA entre duas regiões idênticas e repetidas de microssatélites (REDDY; SARLA; SIDDIQ, 2002). Os marcadores ISSR têm vantagens em sua utilização, em relação a outros marcadores de DNA, por não requererem conhecimento prévio da sequência do DNA a ser amplificada, por produzirem fragmentos multilocos com alto polimorfismo e com grande reprodutibilidade, semelhante ao marcador de Sequência Simples Repetida (SSR), devido ao longo comprimento do primer e por serem de fácil e rápido manuseio, como o marcador de polimorfismo de DNA amplificado ao acaso (RAPD) (BORNET; BRANCHARD, 2001). Em muitas espécies de plantas, modificações no protocolo de reação ISSR e programa de amplificação do DNA se fazem necessárias visando à otimização na geração de dados. A influência de diversos parâmetros na reprodutibilidade e polimorfismos de DNA de diferentes espécies foi observada na amplificação com o marcador ISSR (BORNET; BRANCHARD, 2001).

A partir disso, o objetivo deste trabalho foi otimizar e estabelecer um protocolo de extração de DNA de dendezeiro pelo método CTAB, assim como otimizar a obtenção de marcadores moleculares ISSR úteis na caracterização genética da cultura. 


\section{Material e métodos}

\section{Material foliar e extração de DNA}

As amostras de folhas maduras de dendezeiros adultos (variedade pisífera e tenera) foram retiradas da Coleção de Germoplasma da Estação Experimental Lemos Maia (ESMAI), da Comissão Executiva do Plano da Lavoura Cacaueira (CEPLAC), em UNA, Bahia, Brasil. As amostras de folhas jovens foram coletadas em plantas adultas, da variedade dura, em uma população subespontânea e do lançamento foliar de suas progênies de meios-irmãos com aproximadamente um ano de idade. As extrações foram realizadas com o protocolo modificado de Doyle e Doyle (1990). Inicialmente, mantendo as concentrações dos reagentes do tampão de extração do protocolo original. Depois, com modificações na concentração de alguns reagentes do tampão de extração e suplementação com uma solução de CTAB 10\%, 1,4 M de cloreto de sódio $(\mathrm{NaCl})$ a $65^{\circ} \mathrm{C}$. As modificações no tampão de extração foram feitas combinando diferentes concentrações de polivinilpirrolidone (PVP) (1\%, $2 \%$ e $3 \%)$ com betamercaptoetanol $(0 \%, 0,2 \%$, $0,3 \%$ e $0,4 \%$ ). O tampão de extração com o pó foliar permaneceu, sob agitação, a $65^{\circ} \mathrm{C}$, por 40 min, e a $20 \mathrm{~min}$ da incubação foi adicionado à solução de CTAB $10 \% \operatorname{com} 1,4 \mathrm{M}$ de $\mathrm{NaCl}$ na proporção 1:10 (v/v). A pós 40 min de incubação, foi resfriado à temperatura ambiente por 5 min, centrifugado a $13.000 \mathrm{rpm}$ por $10 \mathrm{~min}$, e o sobrenadante foi transferido para um novo tubo eppendorf. O clorofórmio: álcool isoamílico (24:1) foi adicionado ao sobrenadante na proporção 1:1 (v:v), homogeneizado por 5 min e centrifugado a $13.000 \mathrm{rpm}$ por $10 \mathrm{~min}$. Essa etapa foi repetida duas vezes consecutivas. Após a centrifugação, foi retirado o sobrenadante e adicionado isopropanol gelado na proporção $1: 1$ (v:v), homogeneizado e incubado por $20^{\circ} \mathrm{C}$ por $12-15$ h. Após a incubação, o homogeneizado foi centrifugado por $10 \mathrm{~min}$ a $13000 \mathrm{rpm}$, e descartou-se o sobrenadante. $\mathrm{O}$ precipitado foi lavado com $1 \mathrm{~mL}$ de etanol $70 \%$ e $95 \%$, respectivamente, seco à temperatura ambiente, ressuspendido com $50 \mu \mathrm{L}$ da solução de TE $\left(10 \mathrm{mmol} . \mathrm{L}^{-1} \mathrm{Tris}-\mathrm{HCl}, 1 \mathrm{mmol} . \mathrm{L}^{-1} \mathrm{EDTA}\right.$ $\mathrm{pH} 8,0$ ), contendo ribonuclease A (RNAse A) na concentração de $10 \mu \mathrm{g} / \mathrm{mL}$, incubado a $37^{\circ} \mathrm{C}$ por 30 min e depois estocado a $-20^{\circ} \mathrm{C}$. A eletroforese para a certificação da quantidade e qualidade do DNA foi realizada no gel de agarose $1,5 \%(\mathrm{~m} / \mathrm{v})$ corado com SYBRr ${ }^{\circledR}$ safe $(5 \mu \mathrm{L} / 100 \mathrm{~mL})$ (Invitrogen), tampão Tris-Borato-EDTA (TBE) 1X, por 35 min e $120 \mathrm{~mA}$, e fotodocumentado sob incidência de luz ultravioleta. A quantificação do DNA foi estimada em comparação com o DNA padrão, fago lambda, nas concentrações de 25,50 e $100 \mathrm{ng} / \mu \mathrm{L}$. A quantificação e a qualidade do DNA também foram estimadas no espectrofotômetro (razão de $\lambda 260 / 230$ e 260/280).

\section{Amplificação do DNA}

Para avaliar a viabilidade do DNA extraído e selecionar iniciadores (primers) ISSR, foram utilizados dois protocolos de PCR (I e II) e um programa de amplificação para cada PCR. Foram testados 17 primers ISSR da Universidade de British Columbia (UBC) e SPAR 9. Para a otimização do protocolo (I), foram testadas diferentes concentrações de DNA $(0,5,1,1,5$ e 2,5 ng/ $\mu \mathrm{l})$; cloreto de magnésio $\left(\mathrm{MgCl}_{2}\right)$ (0,93 mmol. $\mathrm{L}^{-1}, 1,875 \mathrm{mmol} . \mathrm{L}^{-1}$ e 3,75 mmol.L $\left.\mathrm{L}^{-1}\right)$; desoxirribonucleotídeos fosfatados (dNTP) $\left(0,25 \mathrm{mmol} . \mathrm{L}^{-1}, 0,50 \mathrm{mmol} . \mathrm{L}^{-1}\right.$ e $\left.1,0 \mathrm{mmol} . \mathrm{L}^{-1}\right)$ e $\operatorname{primer}(1,0 \mu \mathrm{M}$ e $1,5 \mu \mathrm{M})$. O programa de PCR utilizado foi: um ciclo inicial a $94^{\circ} \mathrm{C}$ por $4 \mathrm{~min}$, para desnaturação de toda a fita dupla de DNA, e 35 ciclos subsequentes com desnaturação a $94^{\circ} \mathrm{C}$ por 1 min; temperatura de anelamento (variando com o primer utilizado) por $1 \mathrm{~min}$; e extensão a $72^{\circ} \mathrm{C}$ por $1 \mathrm{~min}$, para a síntese da cadeia complementar; e após o término dos 35 ciclos, seguiu-se com a temperatura, a $72^{\circ} \mathrm{C}$ por $10 \mathrm{~min}$, de extensão final. Inicialmente os 17 primers foram testados nas seguintes condições: tampão da amostra $0,75 \mathrm{X}, \mathrm{MgCL}_{2}\left(0,93 \mathrm{mmol}^{-1} \mathrm{~L}^{-1}\right)$, dNTP $\left(1,0 \mathrm{mmol} . \mathrm{L}^{-1}\right)$, primer $(1 \mu \mathrm{M})$, Taq polimerase $(1,5 \mathrm{U} / \mu \mathrm{L})$ e DNA $(0,5 \mathrm{ng} / \mu \mathrm{L})$, à temperatura de anelamento de $65^{\circ} \mathrm{C}$. Dos 17 , foram selecionados e testados três primers (UBC 844, UBC 87 e SPAR 9) em diferentes temperaturas de 
anelamento $-57^{\circ} \mathrm{C}, 55^{\circ} \mathrm{C}, 53^{\circ} \mathrm{C}$ e $49^{\circ} \mathrm{C}$ - e DNA $(1 \mathrm{ng} / \mu \mathrm{L})$. O primer UBC 844 foi utilizado para testar a amplificação do DNA em diferentes concentrações de DNA (1, 1,5 e 2,5 ng/ $\mu$ l) (dados não apresentados), duas concentrações de $\mathrm{MgCl}_{2}\left(1,875 \mathrm{mmol} . \mathrm{L}^{-1}\right.$ e 3,75 $\left.\mathrm{mmol} . \mathrm{L}^{-1}\right)$ e temperatura de anelamento a $50^{\circ} \mathrm{C}$.

No segundo protocolo (II), foram mantidas as concentrações otimizadas de alguns reagentes do protocolo (I): DNA $(1 \mathrm{ng} / \mu \mathrm{L}) ; \mathrm{MgCl}_{2}\left(1,875 \mathrm{mmol} . \mathrm{L}^{-1}\right)$; dNTP $\left(1,0 \mathrm{mmol} . \mathrm{L}^{-1}\right) ; 1,5 \mathrm{UN}$ de Taq polimerase e água upp (ultrapura). E modificações foram feitas em alguns reagentes nas seguintes concentrações: primer (0,5 pcmol); tampão da amostra $1 \mathrm{X}$ (com KCl 1,25 mL, sem $\mathrm{MgCl}_{2}$ ); e adição da albumina de soro bovino (BSA) $(0,075 \mathrm{mg} / \mathrm{mL})$. O programa de PCR foi o utilizado na amplificação de dendezeiro com marcadores ISSR por Chagas et al. (2015): desnaturação inicial a $94^{\circ} \mathrm{C}$ por $2 \mathrm{~min}$; seguido de 37 ciclos de $94^{\circ} \mathrm{C}$ por $15 \mathrm{~s}$ (desnaturação), $47^{\circ} \mathrm{C}$ por $15 \mathrm{~s}$ (anelamento) e $72^{\circ} \mathrm{C}$ por $1 \mathrm{~min}$ (extensão), finalizando com $72^{\circ} \mathrm{C}$ por $7 \mathrm{~min}$ (extensão final). As eletroforeses foram realizadas em gel de agarose (1,5\%) corado com SYBR ${ }^{\circledR}$ safe $(5 \mu \mathrm{L} / 100 \mathrm{~mL})$ (Invitrogen), tampão TBE $1 \mathrm{X}$ a 100 volts até atingir $3 / 4 \mathrm{do}$ gel. As amostras foram preparadas com o tampão de carregamento xileno-cianol ( $3 \mu \mathrm{L}$ de tampão em $20 \mu \mathrm{L}$ de DNA amplificado). O marcador ladder $(3 \mu \mathrm{L})$ com 100 pares de bases foi incluído nos géis para a eletroforese.

\section{Análise estatística}

As análises foram realizadas com 16 indivíduos (parental materno e suas 15 progênies). Uma matriz binária foi construída a partir da ausência (0) e presença (1) de fragmentos (locos) amplificados com cada marcador ISSR utilizado na amplificação do DNA. A partir desses dados, foi contabilizado o número de locos totais em cada marcador e o número de locos polimórficos. A porcentagem de polimorfismo foi calculada pela relação entre o número de locos polimórficos e o número de locos totais em cada primer. Para determinar a eficiência dos marcadores em detectar polimorfismo, foi calculado o conteúdo de informação polimórfica (PIC) (ROLDANRUIZ et al., 2000):

$$
\begin{aligned}
& P I C_{i}=2 f_{i}\left(1-f_{i}\right) \\
& \text { Em que: } \\
& \text { PIC }=\text { conteúdo de informação polimórfica do primer } \mathrm{i} \text {; } \\
& f_{\mathrm{i}}=\text { frequência de fragmentos amplificados nas amostras com o primer } \mathrm{i} \text {; } \\
& 1-f_{\mathrm{i}}=\text { frequência de fragmentos não amplificados nas amostras com o primer } \mathrm{i} \text {. }
\end{aligned}
$$

\section{Resultados e discussão}

A seleção do tecido foliar apropriado, em plantas adultas e plantas jovens de dendezeiros, é muito importante no processo de isolamento e purificação do DNA, devido à natureza fibrosa e à presença de compostos secundários nas folhas em diferentes fases de desenvolvimento. Nem sempre é possível a retirada das folhas jovens em expansão, nas plantas adultas de dendezeiro, que podem atingir até 30 metros de altura, nem a manutenção de uma boa conservação na coleta e transporte do material foliar em experimentos e em populações naturais de longas distâncias. Como os protocolos utilizados em dendezeiro nem sempre são reproduzidos nas mais diversas situações, apresenta-se neste estudo uma modificação de um protocolo para a extração de DNA e para a amplificação via PCR em folhas maduras e jovens, retiradas de plantas adultas e plantas jovens, com variação no estado de conservação. 


\section{Extração do DNA}

Na extração de DNA de folha de dendezeiro adulto, o pellet (DNA) ficou escuro e de difícil ressuspensão na solução de TE + RNase, porém o aumento na proporção de betamercaptoetanol e PVP melhorou a qualidade do DNA. O precipitado de DNA de coloração escura foi observado na ausência ou em baixas porcentagens de PVP $(1 \%, 2 \%)$ e de betamercaptoetanol $(0 \%, 0,1 \%$ e $0,2 \%$ ) adicionadas no tampão de extração. O precipitado escuro é causado pela oxidação do DNA, devido à presença de polifenois nas amostras foliares, os quais se ligam covalentemente ao DNA, dificultando seu uso em estudos moleculares, mas a oxidação pode ser evitada pela utilização de PVP e betamercaptoetanol (SAHU; TGHANGARAJ; KATHIRESAN, 2012), porém essas substâncias reduzem o rendimento de DNA (POREBSKI; BAILEY; BAUM, 1997).

O protocolo CTAB desenvolvido para extração rápida de DNA em Phoenix dactylifera mostrou-se eficiente para extração de DNA de dendezeiro, em folhas jovens, quando foi modificado com a adição de PVP e betamercaptoetanol (SUZANA et al., 2015). Ying e Zaman (2006) obtiveram DNA extraídos de folhas maduras de dendezeiros, com boa qualidade e rendimento, utilizando um método CTAB modificado com extração em baixas temperaturas e modificações nos tampões padrões utilizados no protocolo. Os principais constituintes das folhas jovens de dendezeiros são ácidos fenólicos, tanino, flavonoide e carboidratos, mas possuem também proteínas, alcaloides, saponina, coumarins, terpenoides e esteroides em quantidades menos expressivas (YIN; ABDULLAH; PHIN, 2013). Folhas maduras contêm maiores quantidades de polifenois, taninos e polissacarídeos (POREBSKI; BAILEY; BAUM, 1997).

A combinação de $3 \%$ de PVP e $0,3 \%$ de betamercaptoetanol no tampão de extração e a adição da solução de CTAB $10 \% \operatorname{com} 1,4 \mathrm{M}$ de $\mathrm{NaCl}$, aproximadamente aos 20 min da incubação a $65^{\circ} \mathrm{C}$, deixou o pellet mais claro e mais fácil de ressuspensão em TE + RNase, e não teve impacto na quantidade de DNA extraído, exceto no DNA extraído de folhas degradadas (55 a $100 \mathrm{ng} / \mu \mathrm{L}$ ) (Figura 1A e 1B). Entretanto, relatos da literatura citam que o aumento na concentração de betamercaptoetanol no tampão de extração aumenta a pureza de DNA, mas reduz o rendimento de DNA extraído, conforme observado por Borges et al. (2009).

As folhas jovens ou maduras do dendezeiro adulto são fibrosas e dificultam tanto a formação do pó foliar quanto a extração do DNA, porém, quando suplementadas com a solução de CTAB 10\%, 1,4 M de NaCl, na fase em que a mistura do pó foliar com tampão de extração está a 20 min de aquecimento a $65^{\circ} \mathrm{C}$, ocorre a solubilização das membranas celulares e a redução da contaminação com polissacarídeos. A adição de $\mathrm{NaCl}$ em concentrações superiores a 0,5 M, juntamente com o CTAB, é conhecida por remover polissacarídeos durante a extração de DNA (SAHU; TGHANGARAJ; KATHIRESAN, 2012). A maioria das amostras extraídas de folhas de plantas adultas apresentou ausência de contaminação por proteínas e fenóis (valores de absorbância na razão de $\lambda 260 / 280$ variaram de 1,22 a 2,07), mas as folhas com degradação resultaram em DNA degradados, fato atribuído ao acondicionamento inapropriado durante sua coleta e transporte. A absorbância razão de $\lambda 260 / 230$ variou de 0,88 a 2,09, sendo a maioria em torno de 1,7. A relação A260/A230 em torno de 1,7 indica que a maioria das preparações não continha polissacarídeo e fenol.

Nas extrações de DNA de folhas de plantas jovens, o aumento crescente nas concentrações de PVP no tampão de extração não alterou a qualidade do DNA obtido, porém a adição de $0,3 \%$ de betamercaptoetanol no tampão de extração e a solução de CTAB $10 \% \operatorname{com~1,4~M~de~} \mathrm{NaCl}$, ao macerado foliar com tampão, melhorou a qualidade e quantidade do DNA (Figura 1C). Os valores de absorbância na razão de $\lambda 260 / 280$ variaram de 0,97 a 1,94, as concentrações variaram de 53,1 a $600 \mathrm{ng} / \mu \mathrm{L}$, e a razão de $\lambda 260 / 230$ variou de 0,64 a 2,18 . 
Figura 1 - A - Eletroforese, em gel de agarose 1,5\% com tampão TBE 1X, mostrando o DNA (1 a 14) extraído de folhas maduras não degradadas (FM) de Elaeis guineensis (dendezeiro) (variedade pisífera e tenera) e DNA padrão lambda (25 e $50 \mathrm{ng}$ ); B - Eletroforese de DNA (1 a 19) extraído de amostras de folhas maduras degradadas (FMD) de Elaeis guineensis (dendezeiro) (variedade pisífera e tenera); C - Eletroforese de DNA extraído de folhas jovens, bem conservadas, de progênies de Elaeis guineensis (dendezeiros), variedade dura, com um ano de idade e DNA padrão lambda $(25,50$ e $100 \mathrm{ng})$

Figure 1 - The eletroforese, made in gel (1,5\% of agarose diluted in a buffer TBE $1 \mathrm{X})$, of the DNA (1 a 14) extracted from mature and not degraded leaves (ML) of Elaeis guineensis (oil palm), (pisifera and tenera variety), and of the lambda standard DNA (25 and $50 \mathrm{ng}$ ); B - The eletroforese of a DNA (1 a 19) extracted from mature and degraded leaves (MDL) of Elaeis guineensis (oil palm) (pisifera and tenera variety); C -The eletroforese of the DNA extracted from young and well-conserved leaves, from progenies of the variety dura of an Elaeis guineensis (oil palm) at one year of age and of the lambda standard DNA (25, 50 and $100 \mathrm{ng})$
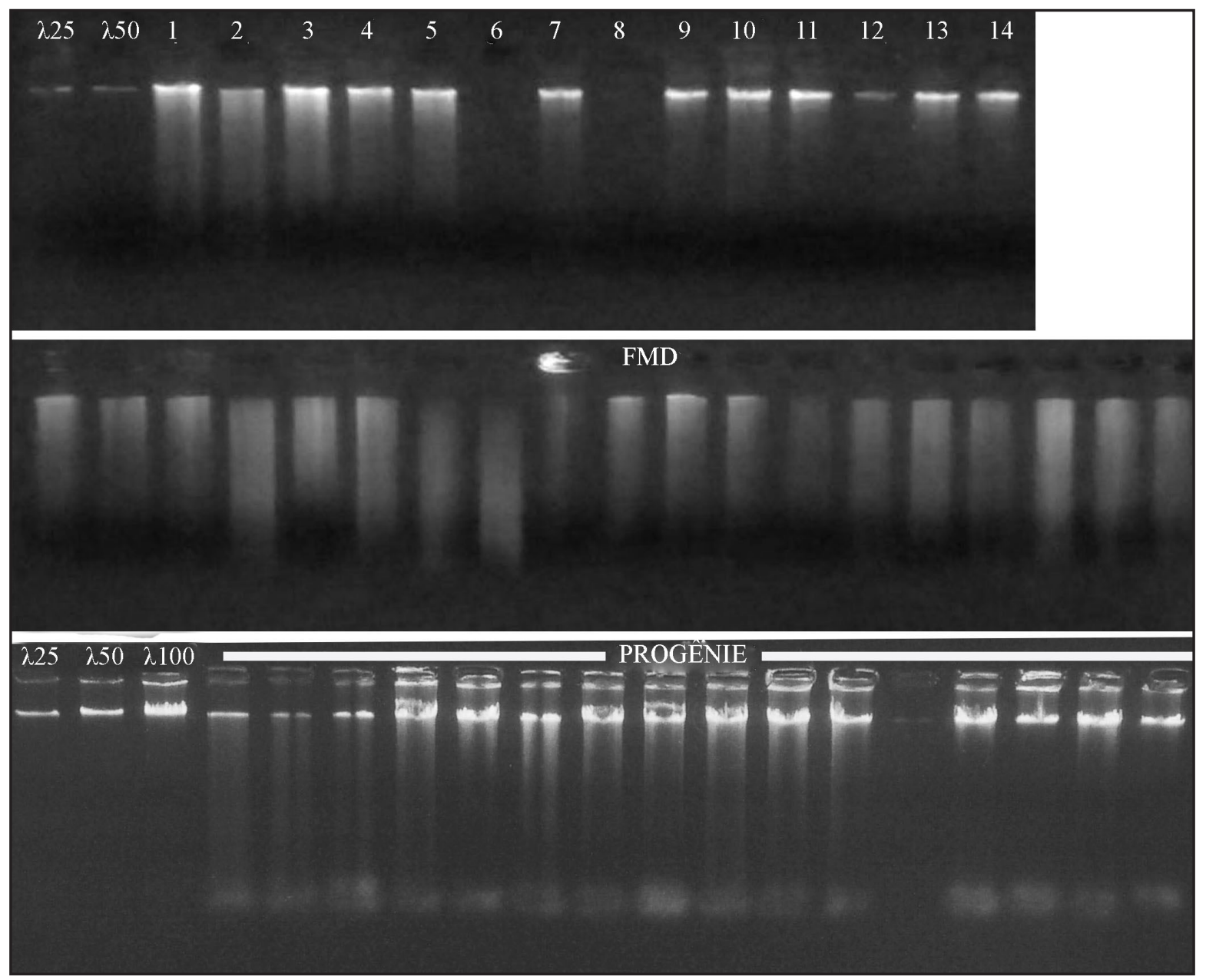

Fonte: Autores (2019) 


\section{Amplificação do DNA e seleção de primers}

As amostras de DNA mostraram-se estáveis, mesmo após armazenamento a $-20^{\circ} \mathrm{C}$, a longo prazo, pois foram submetidas à amplificação logo que extraídas e três anos após sua extração. As amostras de DNA foram viáveis para a amplificação e seleção de iniciadores ISSR com os dois protocolos (I e II), com restrições às amostras obtidas de folhas muito degradadas e notoriamente com o uso do protocolo I. Inicialmente, as amplificações apresentaram bandas com baixa intensidade e ilegíveis com quase todos os17 primers testados (Figura 2A). As temperaturas de anelamento que foram testadas com três primers (UBC844, UBC 87 e SPAR9) e DNA na concentração de $1 \mathrm{ng} / \mu \mathrm{L}$ resultaram em sutis diferenças na qualidade das bandas, como pode ser observado com o primer 844 na Figura 2B. O melhor resultado obtido na amplificação via PCR foi com a concentração de DNA na concentração de $1 \mathrm{ng} / \mu \mathrm{L}$ e 0,1875 mmol.L ${ }^{-1}$ de $\mathrm{MgCl}_{2}$ (Figura 2C).

Com a otimização de reagentes e diferentes temperaturas de anelamento, foi possível a seleção de primers (Figura 2D), mas as amplificações com o DNA de todos os indivíduos apresentaram diferentes intensidades e visibilidades de bandas. Então, foram mantidas as concentrações do dNTP $\left(1,0 \mathrm{mmol} . \mathrm{L}^{-1}\right)$, DNA $(1 \mathrm{ng} / \mu \mathrm{L})$ e $\mathrm{MgCl}_{2}\left(0,1875 \mathrm{mmol} . \mathrm{L}^{-1}\right)$, e foi testada a adição de BSA e concentração mais elevada do primer, com tampão da amostra $1 \mathrm{X}$ e menor temperatura de anelamento no programa de amplificação (protocolo II). Concentrações de primers variando de 10 a $500 \mathrm{pmol} /$ reação foram testadas em várias espécies para a otimização de marcadores ISSR (BORNET; BRANCHARD, 2001). A adição de BSA, aliada à maior concentração de primer $(0,5 \mathrm{pcmol})$, melhorou a intensidade e distinguibilidade das bandas amplificadas a partir do DNA de folhas adultas e de plantas jovens de dendezeiros, exceto em amostras muito degradadas. As diferenças principais entre as duas reações de amplificação foram a concentração do primer e a utilização de BSA. A BSA tem sido utilizada como um aditivo em várias aplicações, incluindo amplificação por PCR, que contêm potenciais inibidores, como os compostos fenólicos (FARELL; ALEXANDRE, 2012).Também, tem sido utilizada com eficiência em amplificações de DNA com marcadores moleculares ISSR em dendezeiros (CHAGAS et al., 2015; GOMES, 2016).

As diferenças nas programações das PCR dos dois protocolos, I e II, utilizados na amplificação do DNA foram: redução no tempo de desnaturação inicial, ligação dos iniciadores e extensão final, número de ciclos da PCR (37) e temperatura de anelamento constante de $47^{\circ} \mathrm{C}$ para todos os primers testados. Com o protocolo II, foi testado o primer UBC 844 e mais seis primers. Entre todos, foram selecionados cinco que apresentaram bandas intensas e legíveis (Figura 2E). O perfil das bandas apresentou uma variação de 350 a 1400 pb dependendo do primer utilizado na amplificação do DNA. Considerando-se o parental materno de dendezeiro subespontâneo e suas 15 progênies, observa-se que os cinco primers amplificaram 23 locos com uma média de 4,6locos por primer (Tabela 1). Foram amplificados de três a seis locos/primer com um a quatro polimórficos/primer. A porcentagem de polimorfismo variou de 20 a $100 \%$. Os primers UBC 834 e UBC 848 apresentaram maior porcentagem de polimorfismo, 100 e 66,6\%, e conteúdo de informação polimórfica (PIC), 0,48 e 0,45, respectivamente. Segundo Roldan-Ruiz et al. (2000), o valor do PIC varia de zero, para marcadores monomórficos, a 0,5 para marcadores polimórficos quando estão presentes em $50 \%$ das plantas. Três dos cinco primers, UBC 807, 810 e 812, apresentaram porcentagem de polimorfismo de 20, 20 e 33,3\%, respectivamente, e com PIC pouco informativo $(0,10 ; 0,22 ; 0,04)$. Em dendezeiro, na variedade dura, deve-se considerar que a base genética é restrita e ocorre alogamia entre parentes, portanto as plantas genitoras e progênies compartilham muitos alelos comuns e, consequentemente, terão muitos locos monomórficos. É possível que seja necessário um número maior de primers, devido ao baixo polimorfismo, para capturar diferenças na variedade dura. Porém os marcadores UBC 834 e 848 foram eficientes em determinar polimorfismo nas amostras de DNA, sugerindo que existe alta variabilidade genética em certas regiões do genoma dessa variedade. 
Figura 2 - Resultado da eletroforese do marcador de peso molecular de $100 \mathrm{pb}$ (L) e DNA de Elaeis guineensis (dendezeiro) amplificado por PCR nas seguintes condições: A - DNA $(0,5 \mathrm{ng} / \mu \mathrm{L})$, tampão da amostra $0,75 \mathrm{X}, \mathrm{MgCl}_{2}\left(0,93 \mathrm{mmol}^{-\mathrm{L}^{-1}}\right), \mathrm{dNTP}\left(1,0 \mathrm{mmol} . \mathrm{L}^{-1}\right)$, primers $\operatorname{ISSR}(1 \mu \mathrm{M})$, Taq polimerase $(1,5 \mathrm{U} / \mu \mathrm{l})$, com temperatura de anelamento de $65^{\circ} \mathrm{C}$; $\mathrm{B}$ - Com

o primer UBC 844 variando a temperatura de anelamento; C-com o primer UBC 844 à temperatura de anelamento de $50^{\circ} \mathrm{C}$, DNA $(1 \mathrm{ng} / \mu \mathrm{l})$ e variando a concentração de $\mathrm{MgCl}_{2}$; D - Com os primers UBC 87, 844 e SPAR 9 à temperatura de anelamento de $50^{\circ} \mathrm{C}$, tampão da amostra 0,75X, $\operatorname{MgCl}_{2}\left(0,93 \mathrm{mmol}_{\mathrm{L}} \mathrm{L}^{-1}\right), \operatorname{dNTP}\left(1,0 \mathrm{mmol} . \mathrm{L}^{-1}\right)$, primer $(1 \mu \mathrm{M})$, Taq polimerase $(1,5 \mathrm{U} / \mu \mathrm{L})$ e DNA (1ng/ $\mathrm{\mu L})$ (Protocolo I); E- Com os primers UBC 843, 810 e 807 utilizando o protocolo II e o DNA de um parental materno $(\mathrm{M})$ e suas progênies

Figure 2 - Result of the electrophoresis of the $100 \mathrm{bp}(\mathrm{L})$ molecular weight marker and amplified Elaeis guineensis (palm oil) DNA, under the following conditions: A- DNA (0.5 ng/ $\mu \mathrm{L})$ amplified with 11 ISSR primers with $0.75 \mathrm{X}$ sample buffer, $\mathrm{MgCl}_{2}(0.93 \mathrm{mmol}$.L-1), dNTP (1.0 mmol.L-1), primer $(1 \mu \mathrm{M})$, Taq polymerase $(1.5 \mathrm{U} / \mu \mathrm{l})$, with annealing temperature of $65^{\circ} \mathrm{C}$;

B- With the UBC 844 primer varying the annealing temperature; C- with UBC 844 primer at annealing temperature of $50^{\circ} \mathrm{C}$, DNA $(1 \mathrm{ng} / \mu \mathrm{l})$ and varying $\mathrm{MgCl}_{2}$ concentration; D - With primers UBC 87,844 and SPAR 9 at annealing temperature $50^{\circ} \mathrm{C}$, sample buffer $0.75 \mathrm{X}, \mathrm{MgCl}_{2}$ (0.93 mmol.L-1), dNTP (1.0 mmol.L-1), primer $(1 \mu \mathrm{M})$, Taq polymerase $(1.5 \mathrm{U} / \mu \mathrm{L})$ and DNA (1 $\mathrm{ng} / \mu \mathrm{L}$ ) (Protocol I); E- With UBC primers 843, 810 and 807 using protocol II and the DNA of a maternal parent $(\mathrm{M})$ and its progenies

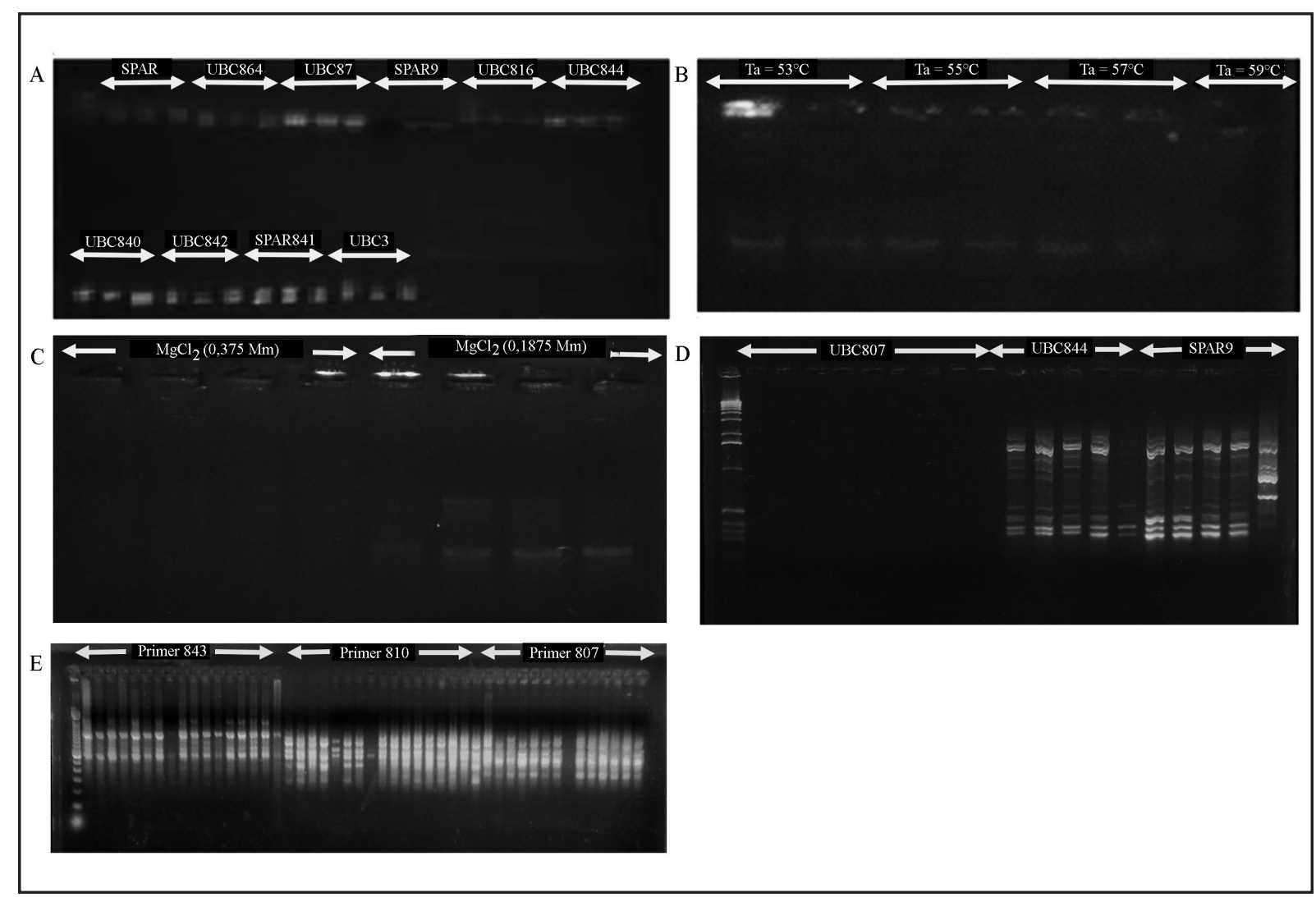

Fonte: Autores (2019) 
Tabela 1 - Relação dos primers ISSR (códigos dos iniciadores) utilizados na amplificação de DNA de Elaeis guineensis (dendezeiro), sequência de nucleotídeos, temperatura de anelamento, número total de locos, número de locos polimórficos, porcentagem de polimorfismo e conteúdo de informação polimórfica

Table 1 - Relationship of ISSR primers (initiator codes) utilized to amplify the Elaeis guineensis (oil palm), nucleotide sequence, annealing temperature, total number of loci, number of polymorphic loci, percentage of polymorphism e, polymorphic information content

\begin{tabular}{lcccccc}
\hline Código do primer & Sequência $\left(\mathbf{5}^{\prime}-\mathbf{3}^{\prime}\right)^{\mathbf{1}}$ & Ta $\left({ }^{\circ} \mathbf{C}\right)$ & $\begin{array}{c}\text { Locos/ } \\
\text { Primer }\end{array}$ & $\begin{array}{c}\text { Locos } \\
\text { Polimórficos }\end{array}$ & \%P & PIC \\
\hline UBC 807 & AGAGAGAGAGAGAGAGT & 47 & 5 & 1 & 20,00 & 0,10 \\
UBC 810 & GAGAGAGAGAGAGAGAT & 47 & 5 & 1 & 20,00 & 0,22 \\
UBC 812 & GAGAGAGAGAGAGAGAA & 47 & 3 & 1 & 33,30 & 0,04 \\
UBC 834 & AGAGAGAGAGAGAGACYT & 47 & 4 & 4 & 100,00 & 0,48 \\
UBC 848 & CACACACACACACACARG & 47 & 6 & 4 & 66,60 & 0,45 \\
\hline Total & & & 23 & 11 & 47,00 & \\
\hline
\end{tabular}

Fonte: Autores (2019)

Em que: ${ }^{1}: \mathrm{D}, \mathrm{Y}, \mathrm{V}$ e $\mathrm{H}=$ nucleotídeos degenerados; $\mathrm{D}=(\mathrm{A}, \mathrm{G}, \mathrm{T}) ; \mathrm{Y}=(\mathrm{C}, \mathrm{T}) ; \mathrm{V}=(\mathrm{A}, \mathrm{C}, \mathrm{G}) ; \mathrm{R}=(\mathrm{A}, \mathrm{G}) ; \mathrm{Ta}\left({ }^{\circ} \mathrm{C}\right)=$ temperatura de anelamento; $\% \mathrm{P}=$ porcentagem de polimorfismo; $\mathrm{PIC}=$ conteúdo de informação polimórfica.

\section{Conclusão}

O método CTAB modificado melhora a qualidade e quantidade do DNA, porém com variações entre amostras, devido, consequentemente, às variações observadas na degradação entre as folhas como resposta do estado de conservação das amostras foliares. A otimização do protocolo da PCR, com o uso de BSA e maior concentração de primer, é importante para a maior eficiência e também para atenuar as diferenças observadas na qualidade das bandas amplificadas no DNA das amostras. As otimizações permitem a seleção de cinco primers, que foram posteriormente utilizados para a amplificação em 13 famílias de dendezeiro, variedade dura, composta de um parental materno e suas progênies.

\section{Agradecimentos}

À Fundação de Amparo à Pesquisa do Estado da Bahia (FAPESB) e à Universidade Estadual de Santa Cruz (UESC), pela concessão de bolsas de iniciação científica (IC) aos dois primeiros autores; à UESC, pelo financiamento da pesquisa; a Jose Inácio Lacerda Moura, pesquisador da Comissão Executiva do Plano da Lavoura Cacaueira/ Centro de Pesquisa do Cacau (CEPLAC/ CEPEC), pelo suporte técnico na obtenção e manutenção do material genético; e a Magno C. Souza, proprietário das Fazendas Boa Vista e Bela Sorte. 


\section{Referências}

BORGES, A. et al. CTAB methods for DNA extraction of sweet potato for microsatellite analysis. Scientia Agricola, Piracicaba, v. 66, n. 4, p. 529-534, jul./ago. 2009.

BORNET, B.; BRANCHARD. M. Nonanchored inter sequence simple repeated (ISSR) markers: reproducible and specific tools for genome fingerprinting. Plant Molecular Biology Reporter, New York, v. 19, p. 209-215, sept. 2001. DOI: 10.1007/BF02772892.

CHAGAS, K. P. T. et al. Seleção de marcadores ISSR e diversidade genética em uma população de Elaeis guineensis. Revista Brasileira de Ciência Agrária, Recife, v. 10, n. 1, p. 147-152, mar. 2015. DOI: 10.5039/agraria.v10i1a5133.

CORLEY, R. V.; TINKER, P. B. H. The oilpalm. Oxford: Wiley-Blackwel, 2015. 674 p.

DOYLE, J. J.; DOYLE, J. L. Isolation of plant DNA from fresh tissue. Focus, Rockville, v. 12 , n. 13, p. 39-40, 1990. Disponível em: http://www.scielo.br/scielo.php?script=sci_ nlinks\&ref=000081\&pid=S0100-2945201300030001800009\&lng=pt. Acesso em: 10 jan. 2019.

FARELL, E. M.; ALEXANDRE, G. Bovine serum albumin further enhances the effects of organic solvents on increased yield of polymerase chain reaction of GC-rich templates. BMC Research Notes, London, v. 5, n. 257, p. 1-8, may 2012. DOI: 10.1186/1756-0500-5-257.

GOMES, H. T. Análise morfoanatômica, bioquímica e molecular de dendezeiros (Elaeis guineensis Jacq.) regenerados por embriogênese somática em sistema de imersão temporária. 2016. Tese (Doutorado em Botânica) - Instituto de Ciências Biológicas da Universidade de Brasília, Brasília, 2016. Disponível em: https://www.alice.cnptia.embrapa.br/alice/bitstream/doc/ 1065516/1/2016HugoTeixeiraGomesParcial.pdf. Acesso em: 01 fev. 2019.

LHASE, L. O. et al. Development of a method for DNA extraction from oil palm leaves and the effects of $\mathrm{pH}$ and ionic strength on nucleic acid quantification. Journal of Biological Methods, San Francisco, v. 3, n. 2, p. 1-6, may 2016. DOI: 10.14440/jbm.2016.80.

NORDIANA, H. M. N. et al. Evaluation of inter simple sequence repeat (ISSR) markers for genetic mapping of an oil palm interspecific hybrid mapping population. Journal of oil Palm Research, Kuala Lumpur, v. 26, n. 3, p. 214-225, sept. 2014. Disponível em: https://bmcresnotes. biomedcentral.com/articles/10.1186/1756-0500-5-257. Acesso em: 05 fev. 2019.

POREBSKI, S.; BAILEY, L. G.; BAUM, B. R. Modification of a CTAB DNA extraction protocol for plants containing high polysaccharide and polyphenol components. Plant Molecular Biology Reporter, New York, v. 15, n. 1, p. 8-15, Mar. 1997. DOI: 10.1007/BF02772108.

REDDY, M. P.; SARLA, N.; SIDDIQ, E. A. Inter simple sequence repeated (ISSR) polymorphism and its application in plant breeding. Euphytica, Dordrecht, v. 128, p. 9-17, nov. 2002.

ROLDAN-RUIZ, I. et al. AFLP markers reveal high polymorphic rates in ryegrasses (Lolium spp.). Molecular Breeding,Dordrecht, n. 6, p.125-134, aug. 2000.

SAHU, S. K.; TGHANGARAJ, M.; KATHIRESAN, K. DNA extraction protocol for plants with high levels of secondary metabolites and polysaccharides without using liquid nitrogen and phenol. ISRN Molecular Biology, New York, v. 6, n. 4, p. 1-6, oct. 2012. DOI: 10.5402/2012/205049.

SATO, M. K. et al. Least limiting water range for oil palm production in Amazon region, Brazil. Scientia Agricola, Piracicaba, v. 74, n. 2, p. 148-156, mar./abr. 2017. DOI: 10.1590/1678-992X2015-0408.

SINGER, R. et al. Oil palm genome sequence reveals divergence of interfertil species in old and new worlds. Nature, London, v. 500, p. 335-340, aug. 2013. DOI: 10.1038/nature12309.

SUZANA, M. et al. A simple and rapid protocol for isolation of genomic DNA from oil palm leaf 
tissue. Journal of oil Palm Research, Kuala Lumpur, v. 27, n. 3, p. 282-287, sept. 2015. Disponível em: https://www.researchgate.net/publication/282254698. Acesso em: 15 fev. 2019.

YIN, N. S.; ABDULLAH, S.; PHIN, C.K. Phytochemical constituents from leaves of Elaeis guineensis and their antioxidant and antimicrobial activities. International Journal of Pharmacy and Pharmaceutical Sciences, Sagar, v. 5, suppl. 4, p. 137-140, dec. 2013. Disponível em: https:// innovareacademics.in/journal/ijpps/Vol5Suppl4/7743.pdf. Acesso em: 13 abr. 2020.

YING, S. T.; ZAMAN, F. Q. DNA extraction from mature oil palm leaves. Journal of Oil Palm Research, Kuala Lumpur, v. 18, p. 219-224, Jun. 2006. Disponível em: https://www.researchgate. net/publication/303328862_DNA_Extraction_from_Mature_Oil_Palm_Leaves. Acesso em: 15 fev. 2019. 